\title{
Full-scale trials of external nitrification on plastic media nitrifying trickling filter
}

\author{
T Mofokeng, AW Muller, MC Wentzel and GA Ekama* \\ Water Research Group, Department of Civil Engineering, University of Cape Town, Private Bag X3, Rondebosch 7701, South Africa
}

\begin{abstract}
The full-scale single-stage tertiary nitrifying trickling filter (NTF) at the Citrusdal Wastewater Treatment Plant provides for external nitrification of unclarified effluent from the facultative aerobic lagoon in order to meet standard effluent ammonia concentration requirements. The apparent ammonia nitrification rate (ApANR, gN/ $\mathrm{m}^{2}$ media surface $\mathrm{d}$ ) of the NTF was sensitive to particulate organic loading rates which were predominantly in the form of algae, and the soluble COD removal rates increased under cold climates. Installation of forced-air ventilation fans improved the nitrification efficiency from $15 \%$ to $43 \%$. An increase in hydraulic loading rate (HLR) by effluent recirculation significantly improved the ApANR, eradicated filter flies and decreased the prevalence of worms. Maximum ApANR of $\sim 1.0 \mathrm{gN} / \mathrm{m}^{2} \cdot \mathrm{d}$ was achieved yielding an ammoniaremoval efficiency of approximately $71 \%$. Profile samples collected along the NTF media depth indicated poor media wetting at low HLR resulting in low ApANR $\left(<0.5 \mathrm{gN} / \mathrm{m}^{2} \cdot \mathrm{d}\right)$. Also during the cold and rainy winter period, poor biofilm activity and prevalence of motile algae were observed, and under low hydraulic loading rates and warmer temperatures, a dominance of filter flies and fly larvae were observed. In contrast, in controlled laboratory studies, ApANRs up to $1.72 \mathrm{gN} / \mathrm{m}^{2} \cdot \mathrm{d}(22.1 \mathrm{mgN} / \ell$ removal) were attained, which, in conformity with full-scale, was also found to be sensitive to hydraulic loading conditions.
\end{abstract}

Keywords: external nitrification, nitrifying trickling filter, unclarified secondary effluent, full-scale, apparent nitrification rates, plastic media

\section{Introduction}

In South Africa, many wastewater treatment plants (WWTPs) extended with nitrification denitrification biological excess $\mathrm{P}$ removal activated sludge (NDBEPRAS) continue to operate their rock-filled trickling filters (TFs). Instead of using them for organics removal and nitrification, there is growing interest in integrating them with NDBEPRAS systems in an external nitrification flow scheme (Hu et al., 2000). In such a scheme, the full influent flow (after primary settling) is discharged to the anaerobic reactor of the NDBEPRAS system, after which the activated sludge is separated from the water by internal settling tanks. The clarified supernatant is pumped to the TF for nitrification and the activated sludge to the anoxic reactor of the NDBEPRAS system, where the nitrified trickling filter effluent rejoins the main NDBEPRAS system. This external nitrification BEPRAS system has several advantages over continuing to use the trickling filters for organics removal and nitrification, such as significantly reduced oxygen demand $(>50 \%)$ and biological $\mathrm{N}$ and $\mathrm{P}$ removal on the full wastewater flow. To date full-scale studies in South Africa have been performed only with rockmedia NTFs, for example the one operated at Daspoort WWTP (Muller et al., 2004; 2006a; b).

This paper describes an investigation on the full-scale operation of the nitrifying TF (NTF) at the $1 \mathrm{M} \ell / \mathrm{d}$ Citrusdal WWTP. This WWTP comprises a 4.2 d retention time lagoon with aeration only in the first half to allow for solids settlement in the

This paper was originally presented at the 2008 Water Institute of Southern Africa (WISA) Biennial Conference, Sun City, South Africa, 18-22 May 2008.

* To whom all correspondence should be addressed.

Im: +2721 650 2585; fax: +2721 689 7471;

e-mail: george.ekama@uct.ac.za second half. The lagoon effluent from the end of the settling zone is pumped to a plastic media NTF unit in order to meet standard effluent ammonia concentration requirements of $<3.0 \mathrm{mgN} / \ell$. The NTF tower is $5.5 \mathrm{~m}$ wide, $5.5 \mathrm{~m}$ long and $5.4 \mathrm{~m}$ high. The plastic media has a specific surface of $142 \mathrm{~m}^{2} / \mathrm{m}^{3}$, yielding a total media surface (A) of $23100 \mathrm{~m}^{2}$ in the tower. The wastewater is distributed over the NTF media through $\sim 100$ garden spray nozzles suspended $0.5 \mathrm{~m}$ above the media. After a single pass (recirculation was added during this investigation) the NTF effluent is discharged to a series of 5 maturation ponds and used for irrigating the golf course in summer, when flow in the Olifants River is low.

The NTF tower was tested over a period of 2 years (Sept 05 to Sept 07 ) to determine its nitrification capacity and to compare this with rock-media NTFs. This information is important in the event that rock media in existing TFs need to be replaced with plastic media. The principle objective was to measure the apparent ammonia nitrification rates (ApANR) under full-scale conditions where ventilation, wetting rates and predator proliferation can affect this rate. The ApANR (gN ammonia nitrified/ $\mathrm{m}^{2}$ media surface $\mathrm{d}$ ) is an overall rate based on NTF influent and effluent ammonia concentrations. This ApANR is a global NTF average and masks any differences in the internal (local) performance of the biofilm or media inefficiency due to poorly wetted areas and patchy biofilm formation due to the presence of predators or clogging by suspended solids. A laboratory-scale NTF was operated in parallel to the full-scale NTF for $323 \mathrm{~d}$ to observe the ApANR rates that could be achieved under controlled conditions.

\section{Literature review}

Extensive research has been done on the design and operation of tertiary NTFs (Gujer and Boller, 1984; 1986; Boller and Gujer, 
1986; Parker et al., 1989; 1995; 1997). Plastic media TFs are efficient for nitrification because of their high void ratio, efficient oxygen transfer and high specific surface area (optimum range of 150 to $200 \mathrm{~m}^{2} / \mathrm{m}^{3}$ ) in comparison to rock-media TFs (Boller and Gujer, 1986; Parker et al., 1989; 1995). Nevertheless, ApANR rates achieved in rock-media NTFs are comparable to plastic media on the basis of the mass of ammonia removed per total media surface area rather than per total media volume (Parker et al., 1989; Muller et al., 2004; 2006a, b). Nitrifiers are obligate aerobes which function optimally in a $\mathrm{pH}$ range of $7.0 \sim 8.5$ and under the presence of low biodegradable soluble COD concentrations. Influent biodegradable soluble COD concentrations of $<30 \mathrm{mgCOD} / \ell$ are reported by Parker et al. (1989) to be sufficiently low to limit competitive heterotrophic organism growth in the top (influent end) of the media. The following parameters are required to maximise the ApANR: Continuous forced-air ventilation, low influent suspended solids and adequate media wetting. In order to ensure adequate media wetting, hydraulic loading rates (HLRs) can be increased by effluent recycle or by operating two NTFs in series with the lead tower being alternated periodically, every 7 to $14 \mathrm{~d}$ (Gujer and Boller, 1984; Parker et al., 1995; Muller et al., 2006a). HLRs below $3.0 \mathrm{~m} / \mathrm{h}$ on plastic media lead to dry patches which are conducive to the development of filter-fly larvae that graze on the nitrifying biofilm (Boller and Gujer, 1986; Parker et al., 1989). Other predators which may be found in NTFs are worms and snails; however, snails are more prevalent in rock-media NTFs. There are various methods of predator control in NTFs (Boller and Gujer, 1986; Lutz, 1990, Parker et al., 1997; Gray et al., 2000): NTF flooding and high HLRs are recommended for biofilm and predator control. The NTF effluent ammonia concentration is required to be $>5.0 \mathrm{mgN} / \ell$ for biofilm growth not to be ammonia-limited (Boller and Gujer, 1986; Parker et al., 1997). Full-scale operation of NTFs is subjected to diurnally varying influent ammonia loading conditions, so measures should be taken to balance the ammonia load such as recycling ammonia-rich digester supernatant under low influent ammonia loading.

\section{Method of investigation}

\section{Full-scale}

The distance from UCT $(200 \mathrm{~km})$ and lack of on-site testing facilities at the Citrusdal WWTP required samples to be kept for long periods before they could be analysed (monthly). At each sample point on the NTF, a filtered and unfiltered sample was collected; both samples were preserved with mercuric chloride ( 1 drop of $8.62 \mathrm{~g} / \ell$ ) and kept frozen until they were analysed after a period of 1 to 4 weeks. The NTF influent and effluent samples were analysed for free and saline ammonia (FSA), filtered and unfiltered COD, nitrate, nitrite and alkalinity. Profile samples (see below) were collected on a monthly basis. The flow rate from the sample ports was used as a qualitative measure (good, average, poor) of the wetting rate at the media section from which the sample was withdrawn. The samples were filtered and preserved on site and analysed for FSA only within $72 \mathrm{~h}$.

\section{Laboratory-scale}

The laboratory-scale experiment was not a scaled-down replica of the full-scale NTF investigation at Citrusdal. The lab
NTF was $1.48 \mathrm{~m}$ tall and comprised $4 \times 0.37 \mathrm{~m}$ long and $0.163 \mathrm{~m}$ diameter cylindrical sections joined with a collared flange and distribution disc. The collars and distribution discs redirected wall flow back over the media in the section below. The NTF column was filled with $170025 \mathrm{~mm}$ diameter plastic spherical balls which yielded a specific area of $109 \mathrm{~m}^{2} / \mathrm{m}^{3}$. It treated final effluent from a laboratory-scale UCT NDBEPR membrane system with zero suspended solids and low COD concentrations (40 to $50 \mathrm{mg} / \ell$, all un-biodegradable). This effluent was dosed with ammonium chloride solution to ensure non-ammonia-limited operating conditions in the NTF (effluent ammonia $>5 \mathrm{mgN} / \ell$ )). At the start of the experimental period, waste activated sludge was recirculated over the media for 2 weeks to accelerate biofilm development on the plastic balls. The ammonia load was applied via an influent pump and the HLR was controlled by a separate NTF effluent recirculation pump.

\section{Preliminary full-scale results}

From preliminary results before this investigation (2001 to Aug 2005) alterations to the Citrusdal NTF were recommended. The NTF relied solely on natural convection for ventilation and was operated at an HLR of around $1.3 \mathrm{~m} / \mathrm{h}$ with no NTF effluent recirculation. Also there were no media-depth sampling ports. The following alterations were implemented before Aug 2005 to improve the nitrification performance (ApANR):

- Four XPELAIR $320 \mathrm{~W}, 50 \mathrm{~Hz}$ forced-air blower fans were installed, one on each NTF face, during July 2002.

- The aerators in the lagoon were repositioned and immersed to their maximum water depth in order to maximise their aeration potential and improve the organic removal capacity the lagoon.

- Four profile sampling ports at 0.8, 1.95, 3.10 and $4.25 \mathrm{~m}$ from the top were drilled through the NTF wall and $2 \mathrm{~m}$ into the media on each of the 4 north, south, east and west faces of the NTF. A tube with a $200 \mathrm{~mm}$ slot $100 \mathrm{~mm}$ from its end was inserted into these ports. The protruding end was closed with a stopper (Fig. 1).

- The HLR was increased from 1.3 to $3.0 \mathrm{~m} / \mathrm{h}$ by adding (during October 2005) an NTF effluent recirculation system with its own pump set, delivery pipe, distribution network and spray-nozzle system in parallel to that of the influent; this was equivalent to a recycle ratio of 1:1.5 with respect to the influent flow.

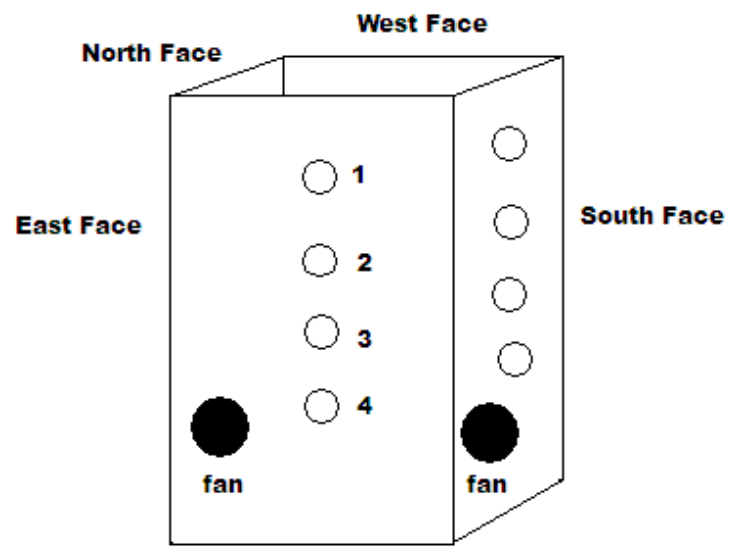

Figure 1

Citrusdal NTF showing position of fans and sampling ports on its four faces 
TABLE 1

Operating parameters of the full-scale nitrifying trickling filter during the period of investigation

\begin{tabular}{|c|c|c|c|c|c|}
\hline Parameters & Units & & Opera & eriods & \\
\hline & & $\mathrm{I}-\mathrm{A}$ & II-A & II-B & $\mathrm{II}-\mathrm{C}$ \\
\hline Season & & Summer & Winter & Winter & Winter \\
\hline Date & & $\begin{array}{c}\text { Oct 05-Feb } 06 \text { \& } \\
\text { Nov06-Mar } 07\end{array}$ & $\begin{array}{c}\text { Aug-Oct } \\
2006\end{array}$ & $\begin{array}{c}\text { Apr-May } \\
2007\end{array}$ & $\begin{array}{c}\text { Jun-Sep } \\
2007 \\
\end{array}$ \\
\hline Wastewater temp $\left({ }^{\circ} \mathrm{C}\right)$ & & warm $(\sim 25)$ & $\operatorname{cold}(\sim 15)$ & $\operatorname{cold}(\sim 15)$ & $\operatorname{cold}(\sim 15)$ \\
\hline Number fans operating & & 3 or 4 & 3 & 2 & 4 \\
\hline Influent flow $\mathrm{Q}_{\mathrm{i}}$ & $\mathrm{m}^{3} / \mathrm{h}$ & 40 & 40 & 40 & 40 \\
\hline HLR (includes influent) & $\mathrm{m} / \mathrm{h}$ & 2.3 & 1.2 & 2.8 & 2.4 \\
\hline Influent ammonia $\left(\mathrm{N}_{\mathrm{aj}}\right)$ & $\mathrm{mgN} / \ell$ & 30.5 & 34.7 & 35.5 & 29.5 \\
\hline Effluent ammonia $\left(\mathrm{N}_{\mathrm{ae}}\right)$ & $\mathrm{mgN} / \ell$ & 10.7 & 22.8 & 26.1 & 15.1 \\
\hline Influent soluble $\left(\mathrm{COD}_{\mathrm{i}}\right)$ & $\mathrm{mgCOD} / \ell$ & 80 & 75 & 82 & 112 \\
\hline Effluent soluble $\left(\mathrm{COD}_{\mathrm{e}}\right)$ & $\mathrm{mgCOD} / \ell$ & 80 & 77 & 65 & 90 \\
\hline Infl. particulate $\left(\mathrm{COD}_{\mathrm{i}}\right)$ & $\mathrm{mgCOD} / \ell$ & 149 & 123 & 153 & 369 \\
\hline Effl. particulate $\left(\mathrm{COD}_{\mathrm{e}}\right)$ & $\mathrm{mgCOD} / \ell$ & 161 & 145 & 122 & 183 \\
\hline Ammonia loading rate & $\mathrm{gN} / \mathrm{m}^{2} \cdot \mathrm{d}$ & $1.21 *$ & 1.37 & 1.51 & 1.24 \\
\hline ApANR & $\mathrm{gN} / \mathrm{m}^{2} \cdot \mathrm{d}$ & $0.92 *$ & 0.58 & 0.40 & 0.61 \\
\hline Total organic LR - OLR & $\mathrm{gCOD} / \mathrm{m}^{2} \cdot \mathrm{d}$ & 10.63* & 8.02 & 8.96 & 10.02 \\
\hline Total organic RR - ORR & $\mathrm{gCOD} / \mathrm{m}^{2} \cdot \mathrm{d}$ & $1.62 *$ & 1.88 & 2.20 & 2.73 \\
\hline
\end{tabular}

Abbreviations: Total OLR- the sum of the particulate and soluble organic loading rates; total ORR- the sum of the particulate and soluble organic removal rates; * $m^{2}$ media surface.

From the limited data for the period 2001 to Aug 2005, the FSA removal efficiency increased from $13 \%$ to $43 \%$ with the introduction of the fans during 2002 (Muller et al., 2005). Despite this improvement, the effluent ammonia concentration was still $>25 \mathrm{mgN} / \ell$ during 2004 which is significantly greater than the standard required of $<3.0 \mathrm{mgN} / \ell$. So the NTF effluent recirculation system was added during 2005 to increase the HLR to improve the FSA removal and investigate the effect of HLR on ApANR. Although uncertain due to the paucity of data, the pre-September 2005 ApANR was very low, between 0.1 and $0.3 \mathrm{gN} / \mathrm{m}^{2} \cdot \mathrm{d}$.

\section{Full-scale nitrifying trickling filter performance}

\section{Operating conditions}

During the 2-year period of investigation from September 2005 to September 2007, the operation of the NTF at Citrusdal was subjected to numerous interruptions as a consequence of the lack of maintenance of the system which resulted in a series of fan and pump failures. Long waiting periods for the repair or replacement of equipment such as pumps and ventilation fans resulted in lengthy periods of non-optimum operating conditions. Hence, the operation of the NTF during the period of investigation has been categorised into periods of similar operating conditions, the operating parameters of which are listed in Table 1. Period I summarises the performance of the NTF during the summer (September to March) and Period II during the winter season (April to August).

Maximum ApANRs of $\sim 1.00 \mathrm{gN} /\left(\mathrm{m}^{2} \cdot \mathrm{d}\right)$ were achieved for a short period during February 2006 (Fig. 2) under ammonia-limited conditions and ammonia loading rates (ALR) of $1.43 \mathrm{gN} / \mathrm{m}^{2} \cdot \mathrm{d}$ and when all the 4 fans were in operation. The lower ApANR of $0.90 \mathrm{gN} / \mathrm{m}^{2} \cdot \mathrm{d}$ observed during the summer period of 2007 (February to March) may be due to insufficient ventilation because only 3 of the fans were in operation while the hydraulic loading rate (HLR) was the same for the summer period of 2006 and 2007. These ApANR yielded effluent ammonia concentrations of between 5 and $10 \mathrm{mgN} / \ell$, which meant the NTF was operating at maximum rate throughout its depth (i.e. non-ammonia limited growth). Single-stage NTFs perform optimally under non-ammonia-limited conditions with effluent ammonia concentrations $>5.0 \mathrm{mgN} / \ell$, thus the effluent requirement of $<3.0 \mathrm{mgN} / \ell$ cannot be achieved in a sustainable manner at the Citrusdal single-stage operated NTF.

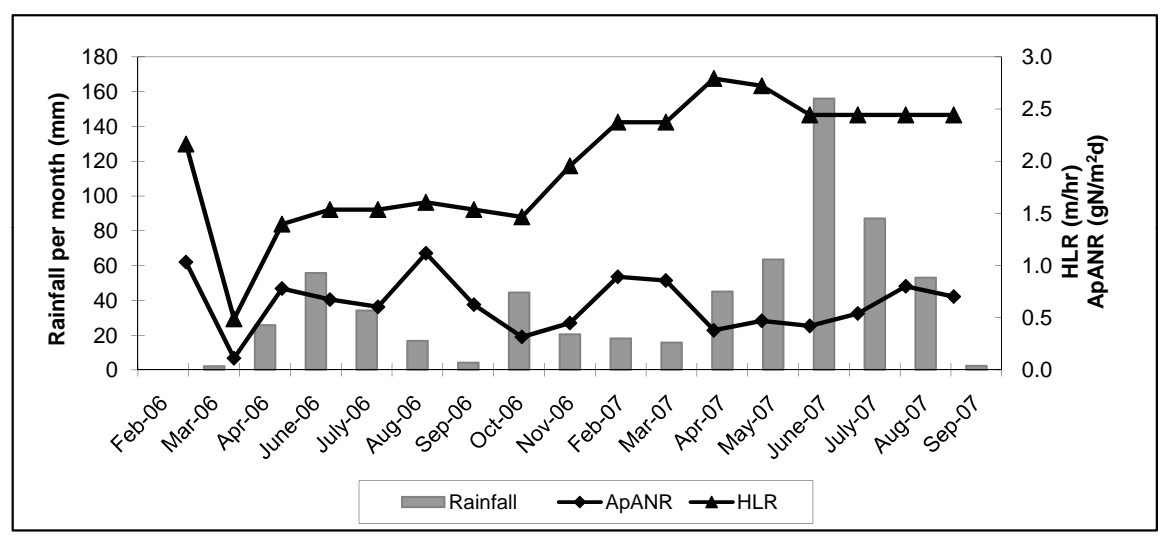

Figure 2

The effect of hydraulic loading conditions on the apparent nitrifying performance of the NTF during the investigation period 


\section{Effect of hydraulic loading conditions on apparent nitrification rates}

Figure 2 illustrates the effect of HLR on the ApANR of the NTF. There was a $90 \%$ decline in ApANR from February to March 2006 as a result of a reduction in the HLR from 2.0 to $0.5 \mathrm{~m} / \mathrm{h}$ due to a series of pump (recirculation and influent) failures and power outages that prevailed for most of 2006. The ApANR increased by $44 \%$ [from 0.50 to $0.90 \mathrm{gN} /\left(\mathrm{m}^{2} \cdot \mathrm{d}\right)$ ] when the HLRs were increased from $1.5 \mathrm{~m} / \mathrm{h}$ in 2006 to 2.3 in 2007. This increase in the HLR was due to a modification of the recirculation pipe work (lower head loss) and replacing its spray nozzles with ones that blocked less quickly. At HLR $<1.5 \mathrm{~m} / \mathrm{h}$, there was a high prevalence of adult filter flies and worms in most of the NTF profile samples, in particular the ones with poor wetting rates. In contrast, at HLR $>1.5 \mathrm{~m} / \mathrm{h}$, the filter fly and worm prevalence was reduced (but not eradicated).

Figure 2 shows that the ApANR increased during the winter of 2006 (rainy season, April to August, HLR $<1.5 \mathrm{~m} / \mathrm{h}$ ) and decreased during the following summer. This is contrary to expectation because wastewater temperature is low in winter $\left(\sim 15^{\circ} \mathrm{C}\right)$ and high in summer $\left(\sim 25^{\circ} \mathrm{C}\right)$. Perhaps media wetting is improved during winter due to high rainfall and low evaporation compared with summer. The ApANR during winter 2007 was significantly lower than that of winter 2006 despite the higher HLRs of $2.3 \mathrm{~m} / \mathrm{h}$. The poor performance of the NTF during winter 2007 is probably due to inadequate ventilation. The ApANR was $0.40 \mathrm{gN} /\left(\mathrm{m}^{2} \cdot \mathrm{d}\right)$ for the period March to April 2007 when only 2 fans were in operation - with all 4 fans in operation, the ApANR increased to $0.61 \mathrm{gN} /\left(\mathrm{m}^{2} \cdot \mathrm{d}\right)$ during the same winter period.

\section{Effect of organic loading on ApANR}

The average total (soluble and particulate) organic loading rate (OLR) during summer period was $9.27 \mathrm{gCOD} /\left(\mathrm{m}^{2} \cdot \mathrm{d}\right)$ (Table 1). This is $11 \%$ higher than the OLR during winter. The particulate OLR was $14 \%$ higher during summer than winter and the summer soluble OLR was $6 \%$ greater that that in winter. This is due to algae proliferating in the facultative lagoon during summer, which results in increased influent particulate COD loading on the NTF. The average total organic removal rate (ORR) (which is the sum of the particulate and soluble organic removal rates) was 1.97 and $2.12 \mathrm{gCOD} / \mathrm{m}^{2} \cdot \mathrm{d}$ for the summer and winter periods respectively. The soluble ORRs during the summer and winter were 0.52 and $0.68 \mathrm{gCOD} / \mathrm{m}^{2} \cdot \mathrm{d}$ respectively, which is equivalent to an apparent soluble biodegradable COD concentration removal of approximately $12 \mathrm{mgCOD} / \ell$ (summer) and $16 \mathrm{mgCOD} / \ell$ (winter). These concentrations are significantly less than the threshold influent biodegradable soluble COD concentration of $<30 \mathrm{mgCOD} / \ell$ reported by Parker et al. (1989). Hence it appears that competitive heterotrophic organism growth in the Citrusdal NTF was limited and thus the sub-optimum performance of the NTF during the investigation was not a consequence of the soluble organics removed by the NTF.

The particulate organics removed by the NTF were 73 and $68 \%$ of the total ORRs observed during the summer and winter, respectively, or $\sim 33 \mathrm{mgCOD} / \ell$ influent (similar in summer and winter). This translates to a particulate COD removal rate of $\sim 1.44 \mathrm{gCOD} /\left(\mathrm{m}^{2} \cdot \mathrm{d}\right)$ or equivalently, a mass removal of 33 $\mathrm{kgCOD} / \mathrm{d})$. Therefore a significant concentration of particulate organics becomes enmeshed in the biofilm, which may have had a negative impact on the nitrification performance.

\section{Internal media performance of the NTF}

Each NTF face was fitted with 4 sampling ports (Fig 1). These ports were $2 \mathrm{~m}$ long cores into the trickling filter media. Profile samples were collected from all 16 sampling ports with a slotted tube that was left in the sampling port for a fixed period of time and the sample volume collected measured. These samples were analysed for free and saline ammonia (FSA) to determine the internal (local) ammonia nitrification rate (ANR). Also, microbial analysis was done on profile samples that had high and low turbidity (suspended solids) and from sampling ports from which low volumes were collected (poor wetting rate). The results of the microbial analysis were used to assist with data evaluation.

Figure 3 illustrates the ammonia concentration profiles observed during the summer periods of the investigation. The profiles of 15/09/05 ( $\downarrow$ ) and 20/10/05 ( $\square$ ) were collected before the NTF effluent recirculation system was installed when the HLR was approximately $1.3 \mathrm{~m} / \mathrm{h}$ and clearly showed much more erratic nitrification behaviour than the other profiles at HLR $\sim 2.7 \mathrm{~m} / \mathrm{h}$. Also, there was a high prevalence of adult filter flies and worms in most of the profile samples from these 2 low-HLR profiles. The approximately linear ammonia depth profiles of

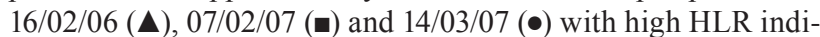
cate uniform biofilm activity with depth which is associated with optimum operation of single-stage NTFs (Boller and Gujer, 1984). Hence, the optimum ApANR obtained during Period I-A is substantiated by the corresponding approximately linear ammonia concentration profiles.

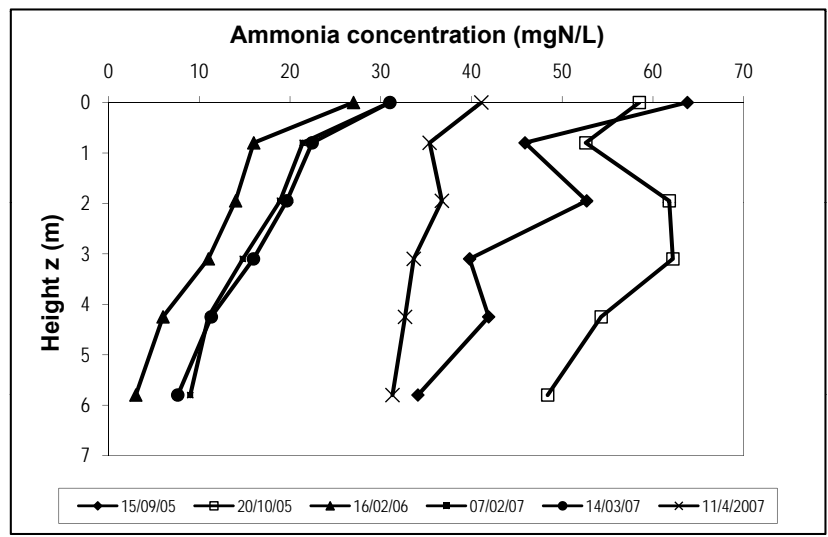

Figure 3

Ammonia concentration profiles during the summer periods of the investigation

The effect of poor ventilation under warm and cold wastewater temperatures is noted in the significant difference in the profiles of 14/03/07 (•) and 11/04/07 (x). During both months the NTF was operating with only 2 of the 4 fans and HLRs were 2.3 and $2.7 \mathrm{~m} / \mathrm{h}$, respectively. However, the maximum and minimum ambient temperatures fell from $33.5^{\circ} \mathrm{C}$ and $15.8^{\circ} \mathrm{C}$ for the $14 / 03 / 07(\bullet)$ profile to $29.8^{\circ} \mathrm{C}$ and $13.1^{\circ} \mathrm{C}$ for the $11 / 04 / 07$ (x) profile. It is speculated that with colder weather and only 2 fans operational, the oxygen transfer may have been a limiting factor for biofilm growth. This could be verified with wastewater temperature data and DO concentration profile measurements (which were unfortunately not measured in this investigation).

The internal performance of the NTF during the winter period of the investigation is illustrated in Fig. 4. These profiles do not indicate a uniform biofilm activity as was the case under optimum operating conditions in some of the summer profiles in Fig. 3. 


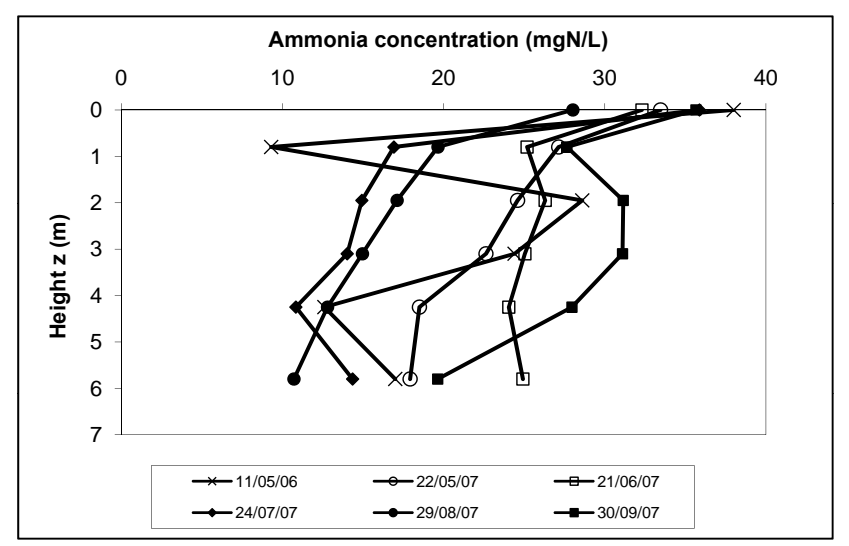

Figure 4

Ammonia concentration profile during the winter periods of the investigation

There was an observed increase in ammonia concentration with depth at the middle section of the NTF (Fig. 4), i.e. between $0.80 \mathrm{~m}$ (Port 1) to $3.10 \mathrm{~m}$ (Port 3, Fig. 1). Analysis of the winter profile samples for microbial activity showed a significant presence of filter fly remains (debris) and worms (Nematoda). Nematoda are primitive unsegmented worms which are found in partially treated raw municipal wastewaters and their presence in this plastic-media NTF was regarded as a negative sign for nitrifying biomass activity. Sunlight penetrating through the cracks of the two-phase brick wall which houses the plastic media stimulates motile algal growth in the NTF, significant traces of which were found in the middle section of all the profile samples. Taken together, the results point to non-uniform biofilm activity. The increase in ammonia concentrations in the middle media sections could be due to ammonia release from the breakdown of the chitinous exoskeleton of the filter fly and other particulates; however, it is doubtful that this ammonia released would be as significant as measured in some of the profiles of Fig. 4.

From the ammonia depth profile, the internal ANRs were calculated from only the approximately linear part of the profile. Figure 5 illustrates the internal ANRs of the NTF as a function of depth. The high ANR displayed in the top section $(0.00$ to $0.80 \mathrm{~m}$, up to Port 1) of the NTF implies that under the optimum operating conditions of Period I-A this section of the NTF media is dominated by nitrifiers. This rate is 3 times higher than the ApANR indicating significant inefficiency in the media when taken overall. This corroborates the observation that the biodegradable soluble COD removed by the NTF is sufficiently low to allow development of nitrifiers at the top of the NTF media. The middle section ( 0.80 to $3.10 \mathrm{~m}$ ) exhibited poor ammonia removal rates which were similar to the removal rates observed from the bottom media section. This implies patchy biofilm development which is characteristic of the lower NTF sections. Stone et al. (1975) found the presence of algae in an NTF treating un-clarified lagoon effluent to have a negative effect on nitrifying biofilm development. Hence it has been inferred that the evidence of motile algal growth observed during the microbial analysis was the chief reason for the poor performance in the middle NTF media region.

\section{Nitrogen balance}

A poor nitrogen balance was achieved from the full-scale results. There were significant discrepancies in the results obtained from

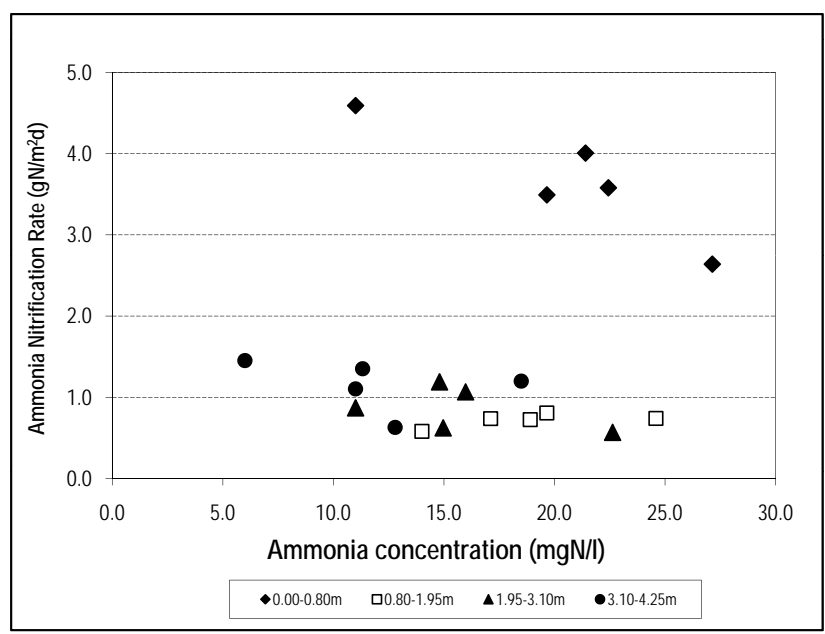

Figure 5

Internal (local) ammonia nitrification rates

the FSA and $\mathrm{NO}_{3}+\mathrm{NO}_{2}$ and alkalinity tests. The long waiting periods ( 3 to 4 weeks) before the samples were analysed for the respective tests could have had an effect on the accuracy of the test results even though the samples were preserved, filtered and frozen until they were analysed for the respective tests. However, the internal performance and microbial analysis of the NTF substantiate the apparent optimum performance of the NTF of $\sim 1.00 \mathrm{gN} / \mathrm{m}^{2} \cdot \mathrm{d}$.

\section{Lab-scale nitrifying trickling filter performance}

The laboratory-scale NTF system operated in a constant temperature laboratory at $20^{\circ} \mathrm{C}$. The influent was the effluent from a membrane laboratory scale UCT NDBEPR system and therefore had a very low COD (40 to $50 \mathrm{mg} / \ell$ ), in fact $25 \%$ lower than the $0.45 \mu \mathrm{m}$ filtered COD. The ALRs and HLRs on the NTF were controlled to achieve optimum nitrifying conditions. During the start-up period, one pump delivered both the influent and effluent recirculation flows with the result that the HLR and ALR were coupled. The apparent ammonia nitrification rate (ApANR) for the first $120 \mathrm{~d}$ was only $0.23 \mathrm{gN} / \mathrm{m}^{2} \cdot \mathrm{d}$. On day 121 the ALR and HLR were decoupled by installing a separate effluent recirculation pump to increase the ApANR. Table 2 lists the operating parameters for the lab-scale system which was operated for a total of $323 \mathrm{~d}$.

The maximum ApANRs achieved during the experimental period of $323 \mathrm{~d}$ was $1.72 \mathrm{gN} /\left(\mathrm{m}^{2} \cdot \mathrm{d}\right)$ when the HLR was highest $(0.86 \mathrm{~m} / \mathrm{h})$. This ApANR is much higher $(70 \%)$ than that in the full-scale system most likely due to better water distribution and media wetting resulting in far greater media efficiency. The effluent ammonia concentration was $>10 \mathrm{mgN} / \ell$ so ammonia-limiting growth conditions did not occur throughout the media depth like in the full scale system. However, there was virtually zero biodegradable organic (COD) loading on the media from the membrane system effluent. In fact, the unfiltered effluent COD was higher than the influent due to biomass sloughing from the media so the system was a net producer of COD. This is distinctly different to the full scale system where some COD removal, and hence some competitive heterotrophic activity, took place.

Figure 6 illustrates the effect of hydraulic loading conditions on the ApANRs. Adult filter flies and worms were observed 
TABLE 2

Operating parameters of the laboratory-scale nitrifying trickling filter during the experimental period

\begin{tabular}{|l|c|c|c|c|c|c|c|}
\hline & $\mathbf{Q}_{\mathrm{i}}$ & $\mathbf{Q}_{\mathbf{R}}$ & $\mathbf{H L R}$ & $\mathbf{N}_{\mathrm{aj}}$ & $\mathbf{N}_{\mathrm{ae}}$ & $\mathbf{A p A N R}$ & $\mathbf{A L R}$ \\
\hline Period & $\mathbf{l} \mathbf{d}$ & $\mathbf{l} / \mathbf{d}$ & $\mathbf{m} / \mathbf{h}$ & $\mathbf{m g N} / \mathbf{l}$ & $\mathbf{m g N} / \boldsymbol{\ell}$ & $\mathbf{g N} / \mathbf{m}^{2} \cdot \mathbf{d}^{*}$ & $\mathbf{g N} / \mathbf{m}^{2} \cdot \mathbf{d}^{*}$ \\
\hline 1 & 101 & 158 & 0.52 & 46.2 & 25.5 & 0.59 & 1.40 \\
\hline 2 & 101 & 230 & 0.66 & 32.1 & 10.6 & 0.65 & 0.97 \\
\hline $\mathbf{3}$ & 144 & 230 & 0.74 & 40.5 & 18.4 & 0.95 & 1.74 \\
\hline
\end{tabular}

Abbreviations: $Q_{I}=$ influent flow rate; $Q_{R}=$ effluent recycle flow rate; $N_{a i}=$ influent ammonia concentration;

$N_{a e}=$ effluent ammonia concentration; $* m^{2}$ media surface.

TABLE 3

\begin{tabular}{|c|c|c|c|c|c|c|}
\hline \multicolumn{7}{|c|}{$\begin{array}{c}\text { TABLE } 3 \\
\text { Comparison of the optimal nitrifying performance of NTFs }\end{array}$} \\
\hline \multirow[b]{2}{*}{ Parameter } & \multirow[b]{2}{*}{ Units } & \multicolumn{5}{|c|}{ SOURCE } \\
\hline & & $\begin{array}{l}\text { Parker et al. } \\
\text { (1989) }\end{array}$ & $\begin{array}{l}\text { Parker et al. } \\
\text { (1995) }\end{array}$ & $\begin{array}{l}\text { Muller et al. } \\
(2006 b)\end{array}$ & This study & This study \\
\hline Research type & & Pilot-scale & Pilot-scale & Full-scale & $\begin{array}{l}\text { Full- } \\
\text { scale }\end{array}$ & Laboratory-scale \\
\hline No. of NTFs & & 1 & 2 & 2 & 1 & 1 \\
\hline Influent flow $Q_{i}$ & $\mathrm{M} \ell / \mathrm{d}$ & 237 & np & 10.6 & 0.96 & $202 \times 10^{-6}$ \\
\hline Media depth & $\mathrm{m}$ & 6.7 & 3.6 & 3.6 & 5.4 & 1.48 \\
\hline Media type & & $\begin{array}{c}\text { Plastic } \\
\text { cross-flow }\end{array}$ & $\begin{array}{l}\text { Plastic } \\
\text { cross-flow }\end{array}$ & Rock & $\begin{array}{l}\text { Plastic } \\
\text { cross-flow }\end{array}$ & $\begin{array}{l}\begin{array}{c}\text { Spherical plastic } \\
\text { balls }\end{array} \\
\end{array}$ \\
\hline Media density & $\mathrm{m}^{2} / \mathrm{m}^{3}$ & 138 & 140 & 45 & 142 & 109 \\
\hline Temperature & ${ }^{\circ} \mathrm{C}$ & 15 & 15 & 22.4 & np & 20 \\
\hline HLR & $\mathrm{m} / \mathrm{h}$ & 5 & 5 & 0.58 & 2.3 & 0.86 \\
\hline ALR & $\mathrm{gN} / \mathrm{m}^{2} \cdot \mathrm{d}$ & np & 2.4 & 1.42 & 1.4 & 2.37 \\
\hline ApANR & $\mathrm{gN} / \mathrm{m}^{2} \cdot \mathrm{d}$ & $2.3^{\mathrm{b}}$ & $2.1^{\mathrm{a}}$ & $1.25^{\mathrm{a}}$ & $1.00^{\mathrm{a}}$ & $1.72^{\mathrm{a}}$ \\
\hline $\mathrm{N}$ removed & $\mathrm{mgN} / \ell$ & 16 & 24.8 & 14.8 & 24.1 & 28.5 \\
\hline Effl $\operatorname{Amm}\left(\mathbf{N}_{\mathrm{ae}}\right)$ & $\mathrm{mgN} / \ell$ & 14 & 1.85 & 2.37 & 8.0 & 10.9 \\
\hline
\end{tabular}

${ }^{a}$ Apparent ammonia nitrification rate

${ }^{b}$ Average nitrification rate (calculated using a model) from measured data.

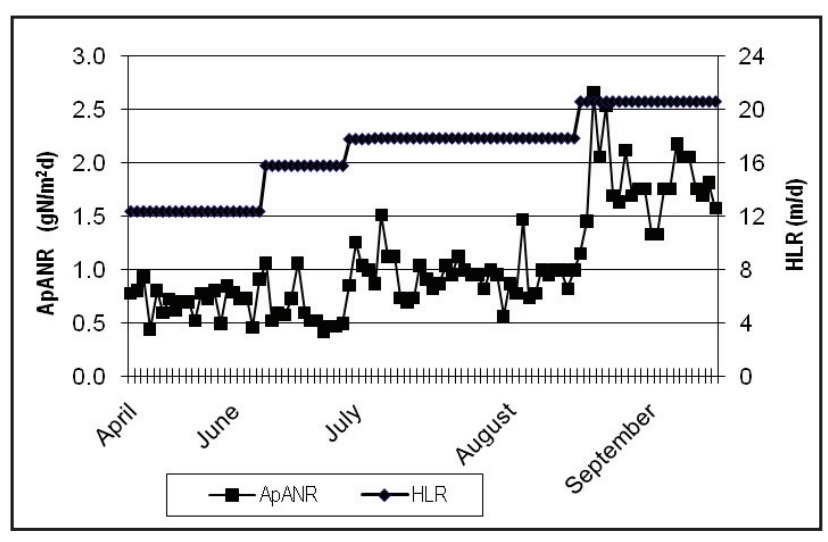

Figure 6

Effect of the hydraulic loading rate on the apparent ammonia nitrification rate of the laboratory-scale nitrifying trickling filter

on the NTF media when the operating HLRs were $<0.66 \mathrm{~m} / \mathrm{h}$. Under operating HLRs $>0.66 \mathrm{~m} / \mathrm{h}$, the adult filter-fly prevalence ceased but the worms were not eradicated even under HLRs of $0.86 \mathrm{~m} / \mathrm{h}$ when the maximum ApANRs were achieved. ApANRs increased from 0.96 to the maximum of $1.72 \mathrm{gN} / \mathrm{m}^{2} \cdot \mathrm{d}$ when the HLR was increased from 0.66 to $0.86 \mathrm{~m} / \mathrm{h}$. This is equivalent to a $44 \%$ increase in ApANRs which indicates the sensitivity of the NTF to hydraulic loading and therefore water distribution and media wetting conditions.

\section{Nitrogen balance}

At the laboratory-scale, a nitrogen balance of $106 \%$ was achieved between ammonia removed and nitrate generated. Also the alkalinity loss calculated from the change in nitrogen species was $114 \%$ of that measured. This validates as accurate the maximum ApANR of $1.72 \mathrm{gN} / \mathrm{m}^{2} \cdot \mathrm{d}$ achieved on the laboratory-scale system.

\section{Comparison of the research results with literature results}

The performance of the full-scale NTF at Citrusdal is compared with the laboratory-scale results of this investigation, pilot-scale results in the literature and full-scale results achieved on rockmedia NTF in South Africa (Muller et al., 2004; 2006a; b) in Table 3. It is evident that rock-media removal rates compare well with those achieved using plastic media. The optimum ApANRs of $1.00 \mathrm{gN} / \mathrm{m}^{2} \cdot \mathrm{d}$ at Citrusdal were achieved under oxygen-limited conditions and at the maximum hydraulic loading capacity of the system. Although this was the maximum performance of the system given the site conditions, the ApANRs were the lowest in comparison to the removal rates listed in Table 3.

The average nitrification rates reported by Parker et al. (1989) were calculated using a model that only takes into account oxygen-limited operating conditions which is different to the calculation of the ApANR. However, it has been included to demonstrate the potential of achieving higher nitrification rates 
with single-stage operated NTFs under higher HLRs. Operating NTFs in series and alternating the lead and follow NTFs every 7 to $14 \mathrm{~d}$ allows effluent ammonia concentrations $<5.0 \mathrm{mgN} / \ell$ to be achieved (provided the ALR is not too high) in a sustainable manner without resulting in ammonia-limited conditions and patchy biofilm growth as would be the case with single-stage operated NTFs (Muller et al., $2006 \mathrm{a}, \mathrm{b}$ )

\section{Conclusions and recommendations}

The following conclusions can be made from the full- and laboratory-scale plastic media single-stage NTFs operated in this investigation:

- The apparent (overall) ammonia nitrification rate (ApANR) is sensitive to the hydraulic loading rate (HLR) - the higher the HLR the higher the ApANR, provided ventilation and ammonia load are not limited. The higher HLR improves water distribution and media wetting and reduces biofilm predator prevalence.

- Lower temperature (air and water) decrease the ApANR. Irregular (increasing and decreasing) ammonia concentration depth profiles supported this observation. Also, inadequate ventilation (due to fan breakdown) during the cold weather is detrimental to the ApANR.

- For the Citrusdal NTF, the irregular ammonia concentration depth profile of the middle media section appeared to be due to algal growth on the media and influent particulates from the lagoon that clog the media.

The following recommendations are made with regard to the application of plastic media NTFs at South African WWTPs:

- Apparent ammonia nitrification rates (ApANR) of $1 \mathrm{gN}$ ammonia nitrified $/ \mathrm{m}^{2}$ media surface $\cdot d$ can be achieved with rock and plastic media. Forced-air ventilation should be considered to avoid oxygen-limited conditions from poor draft ventilation.

- Effluent recirculation should be provided to decouple ammonia (ALR) and HLR. High HLRs are required to improve water distribution, media wetting and to decrease predator prevalence.

- Provided the ApANR is not too high, operating NTFs in series with alternating lead filter every 7 to $14 \mathrm{~d}$ provides for low effluent ammonia concentrations $(<3.0 \mathrm{mgN} / \ell)$ without resulting in ammonia-limited operating conditions which lead to patchy biomass growth. If unclarified secondary wastewater is treated nozzle distribution systems which do not easily block are required (particulates also include filter flies).

- Dedicated operators are required to maintain optimum operating and monitoring conditions, such as maintaining the equipment, and clearing nozzle blockages.
- A minimum of soluble biodegradable and particulate organics should be loaded onto the NTF $(<30 \mathrm{mgCOD} / \ell)$ - higher organic loading rates have a negative impact on nitrification performance so effluent should be well treated and clarified to achieve high ApANRs.

- The nitrifying tower should be a waterproof structure. The double-layer brick wall structure at Citrusdal was found to leak badly, in particular at high HLRs.

\section{References}

BOLLER M and GUJER W (1986) Nitrification in tertiary trickling filters followed by deep-bed filters. Water Res. 20 (11) 1363-1373.

GUJER W and BOLLER W (1984) Operating experience with plastic media tertiary trickling filters for nitrification. Water Sci. Technol. 16 201-213.

GUJER W and BOLLER W (1986) Design of nitrifying tertiary trickling filter based on theoretical concepts. Water Res. 20 (11) 13531362.

GRAY R, RITLAND G, CHAN R and JENKINS D (2000) A Nevada facility controls snails with centrate to meet stringent total nitrogen limits. Water Environ. Technol. 80-83.

HU Z, WENTZEL M and EKAMA G (2000) External nitrification in biological nutrient removal activated sludge systems. Water SA 26 (2) 225-238. http://www.wrc.org.za/archives/watersa\%20archive/2000/ April/1218.pdf

LUTZ M, PRATT A, PARKER D and BRISCHKE K (1990) Full-scale performance of nitrifying trickling fitlers. Proc. $63^{\text {rd }}$ WPCF Conf. October, Washington, DC.

MULLER A, WENTZEL M, SAAYMAN G, VAN DER MERWE S, ESTERHUYSE K and EKAMA G (2004) Full-scale implementation of external nitrification biological nutrient removal at the Daspoort Water Care Works, Tshwane Municipality. Water SA 30 (5) 585-591. http://www.wrc.org.za/archives/watersa $\% 20$ archive/2004/No5special/57.pdf

MULLER A, WENTZEL M, SAAYMAN G, VAN DER MERWE S, ESTERHUYSE C, PRINSLOO J, SNYMAN J and EKAMA G (2006a). Two-years operating experience of full-scale external nitrification BNR activated sludge. Proc. $9^{\text {th }}$ Bienn. WISA Conf. and Exhibition. 21-25 May, Durban, South Africa.

MULLER A, WENTZEL M and EKAMA G (2006b) Estimation of nitrification capacity of rock media trickling filters in external nitrification BNR. Water SA 31 (5) 611-618. http://www.wrc.org.za/ downloads/watersa/2006/WISA $\% 20$ special $\% 20$ ed/1.pdf.

PARKER D, LUTZ M, DAHL R and BERNKOPF S (1989) Enhancing reaction rates in nitrifying trickling filters through biofilm control. J. WPFC. 61 (5) 618-631.

PARKER D, LUTZ M, ANDERSSON B and ASPEGREN H (1995) Effect of operating variables on nitrification rates in trickling filters through biofilm control. Water Environ. Res. 67 (7) 1111-1118.

PARKER D, LUTZ M, JACOBS T, BOWER E, STOWE D and FARMER G (1997) Maximizing trickling filters nitrification rates through biofilm control: research review and full-scale application. Water Sci. Technol. 36 (1) 255-262.

STONE R, PARKER D and COTTERAL (1975) Upgrading lagoon effluent for best practicable treatment. J. WPFC 47 (8) 2019-2040. 